IZA DP No. 2994

Risk Aversion and Schooling Decisions

Christian Belzil

Marco Leonardi

August 2007 


\title{
Risk Aversion and Schooling Decisions
}

\author{
Christian Belzil \\ Centre National de la Recherche Scientifique, \\ CIRANO and IZA \\ Marco Leonardi \\ University of Milan \\ and IZA
}

\section{Discussion Paper No. 2994 \\ August 2007}

IZA

P.O. Box 7240

53072 Bonn

Germany

Phone: +49-228-3894-0

Fax: +49-228-3894-180

E-mail: iza@iza.org

Any opinions expressed here are those of the author(s) and not those of the institute. Research disseminated by IZA may include views on policy, but the institute itself takes no institutional policy positions.

The Institute for the Study of Labor (IZA) in Bonn is a local and virtual international research center and a place of communication between science, politics and business. IZA is an independent nonprofit company supported by Deutsche Post World Net. The center is associated with the University of Bonn and offers a stimulating research environment through its research networks, research support, and visitors and doctoral programs. IZA engages in (i) original and internationally competitive research in all fields of labor economics, (ii) development of policy concepts, and (iii) dissemination of research results and concepts to the interested public.

IZA Discussion Papers often represent preliminary work and are circulated to encourage discussion. Citation of such a paper should account for its provisional character. A revised version may be available directly from the author. 
IZA Discussion Paper No. 2994

August 2007

\section{ABSTRACT}

\section{Risk Aversion and Schooling Decisions ${ }^{*}$}

We develop a non-rational expectation econometric model of sequential schooling decisions. Using unique Italian panel data in which individual differences in attitudes toward risk are measurable (with error), we investigate the effect of risk aversion on the probability of entering higher education. This allows us to characterize the subjective (as opposed to the objective) effect of higher education on marginal risk exposure. Because the measure of risk aversion (the classical Arrow-Pratt degree of absolute risk aversion) is posterior to schooling decisions, it depends on current wealth realizations and we must therefore take into account its endogeneity. We also allow risk aversion to be measured with error. After taking into account both the endogeneity of wealth and measurement error, we find that risk aversion is a key determinant (comparable to parents' educational background) of the decisions to enter higher education. Precisely, risk aversion acts as a deterrent to higher education investment.

JEL Classification: J24

Keywords: risk aversion, ex-ante risk, schooling, subjective beliefs, dynamic discrete choices

Corresponding author:

Christian Belzil

Groupe d'Analyse et de Théorie Economique

CNRS UMR 5824 - University of Lyon 2

93, chemin des Mouilles - B.P.167

69131 Ecully cedex

France

E-mail: belzil@gate.cnrs.fr

\footnotetext{
*We thank Flavio Cunha, Joop Hartog, Winfried Koeniger and Stacey Chen for useful discussions.
} 


\section{Introduction}

Measuring the relationship between risk attitudes and educational choices is a long standing problem in labor economics. This is largely explained by the multiplicity of channels by which schooling may affect risk exposure. Some of these may come from the supply side, while others come from the demand side. Focussing on the supply side, higher education requires to face both direct and psychic costs while academic success may have an inherent random component. On top of this, uncertainty about labor market abilities may also represent a certain form of ex-ante risk.

At the same time, from the demand side perspective, schooling may affect the probability distribution of future labor market outcomes. ${ }^{1}$ In the long run, labor market productivity and earnings may be affected by technological changes, which may be viewed as an additional element of risk from the perspective of the student. On the other hand, when schooling is viewed as facilitating adjustment to technological change, this uncertainty may turn out to favor schooling acquisition (i.e. schooling is a form of insurance). For all these reasons, it is difficult to say whether or not individuals perceive higher education as a truly risky investment, or as a form of insurance.

This paper addresses the following question: Does risk aversion increase or decrease the probability of attending higher education? In order to answer this question, we propose an approach that departs from standard methods which would consist of measuring the marginal risk associated to schooling for all relevant labor market outcomes. Such an approach may turn out to be unproductive if individuals have imperfect information about the distribution functions that generate future labor market outcomes and, instead, are endowed with subjective probabilities that diverge from the objective probability distributions of post-schooling (observable) outcomes. Obviously, in such a case, the Rational Expectation hypothesis has no identifying power and post-schooling panel data on wages and employment outcomes become irrelevant for the purpose of estimating an ex-ante model. ${ }^{2}$

\footnotetext{
${ }^{1}$ For instance, schooling may reduce earnings dispersion by reducing the incidence of unemployment or by raising the job offer probabilities (given unemployment) but it may increase wage volatility if more educated workers find jobs in sectors or occupations where wages (or marginal product) is more volatile.

${ }^{2}$ In a pure Rational Expectations framework, evaluating the marginal risk would require a statistical analysis of the joint distribution of life cycle wages, unemployment, job offer probabilities and grade completion (or failure) probabilities. In particular, it would also
} 
Instead, we propose to measure differences in school continuation probabilities, conditional on individual specific risk aversion. Using unique Italian panel data (the Bank of Italy Survey of Income and Wealth) in which individual differences in attitudes toward risk are measurable, we develop a nonrational expectation econometric model of sequential schooling decisions. ${ }^{3}$ We infer the subjective effect of continuing to a higher grade level on marginal risk exposure, from the estimated effect of risk aversion on the decision to attend higher education. We take into account the potential endogeneity of risk aversion. Our measure is posterior to schooling decisions. Therefore, it depends on current wealth, on background risk, and on individual specific (time invariant) risk aversion. We also allow wealth to depend on individual specific risk aversion .

Our method is based on two fundamental assumptions; namely that (i) choices be made sequentially and, (ii) preferences are time invariant (there must exist an individual specific, time invariant, degree of risk aversion). More specifically, we use the lottery pricing to construct a measure of absolute risk aversion (the Arrow-Pratt measure) and assume that it is composed of two (separately additive) parts; one containing the effect of wealth, background risk and individual specific risk aversion, and a residual measurement error component. In order to allow for non orthogonality between risk aversion and wealth, we also model the distribution of the non-inherited portion of wealth (as measured in 1995) as a function of individual specific risk aversion, schooling, parents backgrounds, and various instruments affecting the transitory part of wealth.

To our knowledge, this is the first empirical paper that finds a significant effect of risk aversion on the probability of entering higher education. Our results indicate clearly that risk aversion is a key determinant of the probability to continue to higher education, Precisely, risk aversion acts as a deterrent to higher education investment. Indeed, we find that individual

require to disentangle persistent unobserved (from the econometrician perspective) heterogeneity from true dispersion, as in Cunha, Heckman and Navarro (2005). This would be difficult to achieve and indeed, as of now, such a comprehensive study does not exist.

${ }^{3}$ Because we do not model how subjective distributions are inferred, the model is not necessarily inconsistent with a standard rational expectation framework. However, we use the term non-rational expectations in order to differentiate our approach from the structural dynamic expected utility models, in which Bellman equations are solved explicitly, for a given set of beliefs. Keane and Wolpin (1997) is the seminal piece in the structural literature on schooling. See Belzil (2007) for a comprehensive survey of the literature. 
risk aversion is virtually as important as parental education in explaining access to higher education. The disincentive effect of risk aversion on the decision to enter higher education is robust to the allowance for risk aversion to affect the decision to continue to senior high school, conditional on terminating junior high school. Our results also point out to the impossibility of treating measured risk aversion as exogenous. Measurement error is found to be very important.

The paper is constructed as follows. In Section 2, we present some background material and review the most important literature. In Section 3, we present a brief description of the Italian schooling system. In Section 4, we discuss the Bank of Italy Survey of Income and Wealth (SHIW) and provide details about the measure of risk aversion used in our analysis. The econometric model is described in Section 5. Section 6 contains a brief overview of the model specifications. The main empirical results are in Section 7. The economic interpretation of the results, along with the conclusion, are found in Section 8.

\section{Background an Relevant Literature}

As of now, most of the work devoted to the link between risk and schooling has been theoretical in nature and often confined to relatively stylized two-period models. In general, theoretical results stress that earnings uncertainty may depress human capital investment (Lehvari and Weiss, 1974, and Olson, White and Sheffrin,1979). Empirical work remains scarce and is rather inconclusive. This is understandable. The degree of complexity that characterizes the effect of schooling on risk exposure is high.

In the earlier literature, a few descriptive analyses of the variability of empirical age/earnings profile have been carried out. Mincer (1974) investigates how the variance of earnings differs across schooling levels over the life cycle while Chiswick and Mincer (1972) use age earnings profile to investigate time series changes in income inequality. However, the notion of variability is usually an "ex post" notion which may have little to do with "ex ante" risk. In the more recent wage inequality literature, it is customary to analyze wage dispersion (basically the variance) within education groups. More recently, Lemieux (2006) shows that the variance of wages is higher within the more educated group and discusses the increase in college enrollments that took place during the period over which rising wage inequality has been 
documented for the US.

Focussing on risk (as opposed to heterogeneity), Shaw (1996) develops a model of the joint investment in financial wealth and human wealth to show that human capital investment is an inverse function of the degree of relative risk aversion. Using data from the Survey of Consumer Finances and according to the theory, she finds that wage growth is positively correlated with preferences for risk taking. Differently from us she measures individualspecific risk aversion using information on the allocation of wealth to risky financial assets or from a survey question about that desired allocation. She also finds that more educated individuals are also more likely to be risktakers however she does not address the endogeneity issue between education and risk aversion. In a recent paper, Palacios-Huerta (2003) presents an empirical comparison of the properties of risk-adjusted rates of return to schooling within an intertemporal model, using mean-variance spanning techniques, but does not model individual decisions. ${ }^{4}$ Chen (2006) analyses the effect of higher education on the variance of the log wage regression, using standard sample selectivity arguments, but disregards attitudes toward risk in her analysis. Therefore, it is important to note that, as of now, the link between ex-ante risk and schooling has not been established empirically. ${ }^{5}$

Knowing the degree of education selectivity based on individual differences in risk aversion is fundamental. For instance, the relatively insignificant change in college enrollment that has been observed in the 1990's after the well documented increase in returns to schooling that took place over the 80's in the US (and in other countries), documented in Card and Lemieux (2000), suggests that behavior toward risk may be a possible explanation. Economists are currently unable to say if (and to what extent) schooling acquisition is a risky investment although the issue is starting to raise a significant level of interest. However, as indicated by the recent surge in empirical papers devoted to the issue, the link between risk and education is now regarded as an important topic. ${ }^{6}$

\footnotetext{
${ }^{4}$ Basically, the mean-variance spanning technique amounts to quantifying the effect of introducing a new asset on the mean-variance of another benchmark asset.

${ }^{5}$ The distinction between inequality and ex-ante risk is discussed in Cunha and Heckman (2007).

${ }^{6}$ For instance, Labour Economics devotes an entire (forthcoming) issue to this single topic.
} 


\section{The Schooling System in Italy}

The Italian schooling system is composed of four levels: elementary, lower high school, upper high school and college. Elementary school is typically attained at age 11 (equivalent to 5 th grade) and lower secondary school is typically attained at age 14 (equivalent to 8th grade). For the period under consideration the compulsory schooling was elementary school until 1962 and lower secondary afterwards. The reform of compulsory schooling in 1962 does not have implications on our analysis because we look at the effect of risk aversion only on senior high school and college. Compulsory schooling laws explain the high percentage of those who have elementary (14\%) or lower secondary school (32\%) as the highest attained degree in Table 1. Table 1 also shows that the percentage of the population with a college degree is much lower in Italy (14\%) than in the US and that a large fraction (38\%) of the Italian population holds a secondary school degree. There are four types of secondary schools: Liceo are the traditional high school to access university level education. Other choices are technical, vocational schools or art schools and schools for teachers. These choices give also an optional access to university and at the same time develop professional and technical skills. After lower secondary school, one may also choose professional 3years courses which do not grant access to university but provide skills for determined professions. In our data these are coded as lower secondary. Typically the secondary school (or senior high school) title is attained at age 18. At this age a year of military service is compulsory but can be postponed to the end of university studies for those who decide to go to college (also referred to as higher education).

\section{The Bank of Italy Survey of Income and Wealth}

The 1995 survey of SHIW collects information on consumption, income and wealth in addition to several household characteristics for a representative sample of 8,135 Italian households. 


\subsection{Measuring Risk Aversion}

The 1995 survey contains a question designed to elicit risk aversion attitudes. Each head of household is asked to report the maximum price he/she is willing to pay to participate to an hypothetical lottery. The question is worded as follows:

"We would now like to ask you a hypothetical question that we would like you to answer as if the situation was a real one. You are offered the opportunity of acquiring a security permitting you, with the same probability, either to gain a net amount of 10 million lire (roughly 5,000 dollars) or to lose all the capital invested. What is the most you are prepared to pay for this security?"7

The respondent can answer in three possible ways: 1) give the maximum price he/she is willing to pay, which we denote as bet; 2) don't know; 3) don't want to participate. Of the 8,135 heads of household, 3,483 answered they were willing to participate and reported a positive maximum price they were willing to bet (prices equal to zero are not considered a valid response).

The question has a large number of non responses because many respondents may have considered it too difficult. For our purposes the relationship between non-response and schooling is of particular interest. Those who responded to the lottery question are on average 6 years younger than the total sample and have higher shares of male-headed households (79.8 compared to 74.4 percent), of married people (78.9 and 72.5 percent respectively), of selfemployed (17.9 and 14.2 percent) and of public sector employees (27.5 and 23.3 percent respectively). They are also somewhat wealthier and slightly better educated (1.3 more years of schooling). However, the small difference in education between the total sample and the sample of respondents seems to suggest that - in so far as education is also a proxy for better understanding- non-responses can be ascribed only partly to differences in the ability to understand the question.

At a theoretical level, it is easy to show that there is a one-to-one correspondence between the value attached to the lottery and the degree of risk aversion. For a given wealth $w_{i}$, and a potential gain $g_{i}=10$ million lire, the

\footnotetext{
${ }^{7}$ In other words, the expected value of entering the lottery is $0.5 \cdot(10,000,000-$ bet $)$. The interviews were conducted by professional interviewers at the respondents' homes and to help the respondent to understand the question the interviewers showed them an illustrative card and were ready to provide explanations (for more details see Guiso and Paiella, 2005).
} 
optimal bet $b_{i} t_{i}$, must solve the expected utility equation:

$$
U_{i}\left(w_{i}\right)=\frac{1}{2} U_{i}\left(w_{i}+g_{i}\right)+\frac{1}{2} U_{i}\left(w_{i}-b_{e} t_{i}\right)=E U\left(w_{i}+R_{i}\right)
$$

where $R_{i}$ represents the return (random) of the lottery. Taking a secondorder expansion, and noting that $R_{i}$ is also the maximum purchase price bet $_{i}$, we get that

$$
E U\left(w_{i}+R_{i}\right) \approx U_{i}\left(w_{i}\right)+U_{i}^{\prime}\left(w_{i}\right) E\left(R_{i}\right)+\frac{1}{2} U_{i}^{\prime \prime}\left(w_{i}\right) E\left(R_{i}\right)^{2}
$$

It is therefore possible to express risk aversion as a function of the parameters of the lottery and the value of the bet of each individual. Substituting (2) into (1), we obtain the following expression for the Arrow-Pratt measure of absolute risk aversion (Guiso and Paiella, 2001):

$$
A\left(w_{i}\right) \simeq \frac{-U_{i}^{\prime \prime}\left(w_{i}\right)}{U_{i}^{\prime}\left(w_{i}\right)}=4\left(5-\frac{\text { bet }_{i}}{2}\right) /\left(10^{2}+\text { bet }_{i}^{2}\right)
$$

In general, the degree of risk aversion depends on $U_{i}($.$) , on consumer$ endowment $w_{i}$, and on background risk. The valid responses to the question - bet - range from 1,000 lire to 100 million lire (in equation 3 the variables are scaled by 1 million lire). Of the 3,483 heads with a positive bet, 3,358 have an $A\left(w_{i}\right)>0$ which implies that they are risk averse individuals, 125 are risk neutral and 44 are risk lovers. Although the majority of the respondents are risk averse and only $5 \%$ of the sample is either risk-neutral or risk-loving, there is a large heterogeneity in the degree of risk aversion within the risk averse individuals which shows that preferences are very heterogenous with respect to risk.

Guiso and Paiella (2001) discuss in details the main advantages of this estimate of absolute risk aversion relative to those already in the literature. They underline that the lottery represents a relatively large risk. In fact, ten million lire corresponds to just over 5,000 dollars and the ratio of the expected gain of the hypothetical lottery to the annual average Italian household consumption is 16 percent. This is an advantage since expected utility maximizers may behave as risk neutral individuals with respect to small risks even if they are risk-averse to larger risks. Thus, facing consumers with a relatively large lottery may be a good strategy to elicit risk attitudes.

It should be noted that this measure of risk requires no assumption on the form of the individual utility function and extends to risk-averse, risk-neutral 
and risk-loving individuals. This lottery question has been used to study the relationship between risk aversion and several household decisions. ${ }^{8}$

\subsection{Wealth}

The SHIW data are particularly accurate in the measurement of household wealth. Wealth is defined as the total of financial and real assets net of household debt. Financial wealth is given by the sum of cash balances, checking accounts, savings accounts, postal deposits, government paper, corporate bonds, mutual funds and investment in fund units and stocks. Real assets include investment real estate, business wealth, primary residence and the stock of durables.

We also identify five variables which measure unexpected changes in wealth. Such measures are the capital gain on one's first house property ${ }^{9}$, the age of the father of the head of household (six dummies: father born before 1910, born 1910-1919 and born 1920-29...born after 1950) as a proxy of inherited wealth, an indicator of house ownership as a result of gift or bequest, the sum of settlements received related to life, health, theft and casualty insurance and the contributions (in money or gifts) received from friends or family living outside the household dwelling. These variables are indicated in Table 1 as capital_house, six dummies coh_f, housegift, insurance and friendsmoney.

\footnotetext{
${ }^{8}$ Guiso and Paiella (2005) use the question on risk aversion to analyze occupation choice, portfolio selection, insurance demand, investment in education (in the linear OLS case) and migration decisions. They find substantial effects of this measure of risk aversion in ways that are consistent with the theory i.e. that more risk averse individuals choose lower returns in exchange for lower risk. They find for example that being risk averse increases the probability of being self-employed by $36 \%$ of the sample mean and the probability of holding risky assets by $42 \%$ of the sample mean. They also find that being risk averse as opposed to being risk neutral or risk prone (i.e. they use a risk-averse dummy), lowers education by one year on average.

${ }^{9}$ This is a measure of windfall gains (or losses) on housing constructed using data on house prices at the province level over the years 1980-1994. For homeowners, we compute the house price change since the year when the house was acquired or since 1980 if it was acquired earlier. To tenants, we attach the house price change since the year when they started working or since 1980. This can be justified on the ground that they start saving to buy a home as soon as they start working.
} 


\subsection{Background risk}

In a world of incomplete markets, risk aversion may vary not only because of heterogeneity in tastes but also because individuals face environments that differ in terms of background risk. ${ }^{10}$ As a measure of background risk we take two proxies.

The first measure of background risk is intended to be a measure of aggregate risk at the local level. It is obtained in the following way: For each province we regress the log of GDP per capita in 1980-1995 on a time trend and compute the variance of the residuals. We then attach this estimate to all households living in the same province. This measure is significantly positively related to risk aversion.

The second measure of background risk is based on four questions on labor income expectations that are asked to half of the overall sample in a special section of the 1995 SHIW questionnaire. Since these questions were addressed to only half the sample and of those interviewed only about $60 \%$ replied, the number of valid observations is vastly reduced (940) with respect to the number of those who responded to the risk aversion question $(3,483)$. Households were asked four questions on the perceived probability of being employed over the twelve months following the interview and the variation in earnings if employed. We use this information to construct a measure of the coefficient of variation of the distribution of future earnings following Guiso, Jappelli and Pistaferri (2002). The employed and job seekers are asked to report, on a scale from 0 to 100, their chances of keeping their job or finding one in the next twelve months - denote as $p$. Each individual assigning a positive probability to being employed is then asked to report the minimum -minlav- and the maximum -maxlav- income he expects to earn if employed and the probability of earning less than the midpoint of the distribution of future earnings - probltx- conditional on working. These data (minlav, maxlav and probltx) can be combined to obtain an estimate of expected earnings $E(y)$ - and their variance $-\operatorname{Var}(y)$ - which we use to proxy background risk. ${ }^{11}$ The coefficient of variation $c v=\frac{s d(x)}{E(x)}$ is calculated using:

$$
\begin{aligned}
E(x) & =p E(y)+(1-p) b \\
\operatorname{Var}(x) & =p \operatorname{Var}(y)+p(1-p)[E(y)-b]^{2}
\end{aligned}
$$

\footnotetext{
${ }^{10}$ See Gollier (2001).

${ }^{11}$ The formula used is on page 252 of Guiso, Jappelli and Pistaferri (2002).
} 
where $b$ is a measure of imputed expected unemployment benefits. ${ }^{12}$

\subsection{Sample selection}

Apart from the lottery question, we use information on the level of education attained by the head of household, as well as variables such as age, gender, region of birth, parental education and parental occupation. This set of variables is comparable to those which are used in US studies based on the National Longitudinal Survey (NLS). We select the sample of all heads with a valid answer to the lottery question $(3,483)$ and eliminate those who report a missing value in any of the following variables: education, age, gender, region of birth, education and occupation of the head's father and mother, subjective measure of income uncertainty. This selection process leaves us with a final sample of 940 heads of household.

The original schooling variable takes five possible values (1 to 5) corresponding to no education, elementary school (typically attained at 11 years of age), junior high school (attained at 14), senior high school (attained at 18), university degree (attained at 23-24). ${ }^{13}$

Table 1 shows the descriptive statistics of the sample. In the estimation we use dummy variables derived from the original variables. There are five dummy variables indicating the level of education attained by the individual (no qualification, elementary school, lower high school, upper high school, university degree or higher), three dummies - north, centre and southfor the region of birth, one sex dummy (female=1), and a complete set age/cohort indicators. ${ }^{14}$ In addition we have one dummy each - edu_father and edu_mother - respectively for the level of education attained by the individual's father and mother (less than high school $=0$, high school or more $=1$ ), and four occupation dummies for blue collar, white collar, self employed and unoccupied for each parents' occupation. These variables are denoted bluecollar_f, whitecollar_f, selfempl_f, unempl_f for the father and bluecollar_m, whitecollar_m, selfempl_m, unempl_m for the mother. There also

\footnotetext{
${ }^{12}$ We thank Luigi Pistaferri for providing his routines to impute benefits.

${ }^{13}$ We actually have information about post-university degree, but the number of individuals being too small, we cannot really estimate the transition to post-graduate studies.

${ }^{14}$ These binary indicators are $20-25,26-30,31-35, \ldots .$. until 75 or more. This may be important as, before 1968, legal restrictions limited the accession to college only to those who had a high school degree in classical or scientific studies, since 1968 accession to college is open to any type of high school degree.
} 
the measures of background risk (var_gdp and $s u b j \_r i s k$ ) and of wealth and the exogenous changes in wealth explained above.

Table 2 describes the empirical distribution of our measure of risk aversion $A\left(w_{i}\right)$ in the sample of 940 heads. The proportion of risk-neutral and riskaverse individuals is very similar to the one in the sample of 3,483 families (around $5 \%$ ), the distribution of $A\left(w_{i}\right)$ looks similar to the original sample of 3,483 families with a valid response to the lottery question (second column of Table 2).

\section{The Econometric Model}

We model schooling decisions as a reduced-form dynamic discrete choice model in which the hazard function (the drop-out rate) depends on measures of parental background, individual specific heterogeneity and an individual specific measure of permanent risk aversion. The grade transition model may be regarded as an approximation to a sequential dynamic programming model, in which subjective beliefs are not specified. This particular aspect of the grade transition model is the cornerstone of our econometric methodology, since we do not want to impose any distributional assumptions on subjective beliefs. ${ }^{15}$ Our method is therefore based on two fundamental assumptions; namely that (i) choices be made sequentially and, (ii) preferences are time invariant (there must exist an individual specific, time invariant, degree of risk aversion).

\subsection{A Model of Grade Transition}

The conditional probability (hazard rate) of stopping at grade $g$ for individual $i$, denoted $H_{g i}$, is denoted;

$$
H_{g, i}=\Lambda\left(U_{g, i}\right) \text { for } g=1,2, . . G
$$

where

$$
U_{g, i}=\alpha_{g, i}+\beta_{g}^{\prime} X_{i}+\delta_{g} \cdot R A_{i}
$$

\footnotetext{
${ }^{15}$ Precisely, we do not want to dictate how higher education affects the second (or higher) moment $(\mathrm{s})$ of
} 
and where $G$ is the second highest grade level (senior high school). In our framework, $H_{G, i}$ is the probability of dropping out after having completed senior high school (the probability of entering higher education is $\left(1-H_{G, i}\right)$. Similarly, $H_{G-1, i}$ is the drop out probability after completing junior high school. The term $\alpha_{g, i}$ represents an individual/grade specific intercept term, $X_{i}$ is a vector of observable characteristics, and $\beta_{g}^{\prime}$ represents a grade specific vector of parameters measuring the effects of these characteristics. The variable $R A_{i}$ represents the permanent part of individual specific risk aversion and $\delta_{g}$ is a grade specific parameter. Note that the model is general enough to take into account that the marginal effect of risk aversion may be positive at some grade level and negative at another. This would be important if marginal risk exposure changes substantially with grade level. ${ }^{16}$

We assume that

$$
\alpha_{g, i}=\alpha_{0 g}+\alpha_{g} \cdot \theta_{i}
$$

and that $\theta_{i}$ is drawn from an unknown distribution which is approximated by a discrete distribution with $K$ points of support. As we include an intercept term in the transition probability, we normalize one support point (namely $\left.\theta_{1}\right)$ to 0 .

$\Lambda($.$) is approximated with a mixture of 5$ normal random variables: that is

$$
\Lambda(.)=\sum_{m=1}^{M=5} P_{m}^{g} \cdot \Phi\left(. ; \mu_{m}^{g}, \sigma_{m}^{g}\right)
$$

where $P_{m}^{g}$ is the mixing probability and $\Phi\left(\mu_{m}^{g}, \sigma_{m}^{g}\right)$ denotes the normal cumulative distribution function with mean $\mu_{m}$ and variance $\sigma_{m}^{2}$. Further details are presented in sub-section 5.4.

\subsection{A Model of Absolute Risk Aversion}

As the risk aversion information contained in the SHIW is posterior to the period when schooling decisions were made, we construct a non-linear factor model that allows to identify individual specific permanent risk aversion.

\footnotetext{
${ }^{16}$ This is indeed likely to happen because the supply side risks (such as the failure probability) are likely to be located mostly at university level while the demand side risk may entail marginal risk variability at lower grade levels (for instance, earnings risk exposure may change substantially when going from junior high school to senior high school).
} 
We first specify a flexible model of the Arrow-Pratt measure of risk aversion, $A_{i, 95}($.$) , which is assumed of the following form$

$$
A_{i, 95}(.)=\bar{A}_{i, 95}\left(\text { Wealth }_{i, 95}, \text { Background risk, } R a_{i}\right)+\varepsilon_{i, 95}^{r}
$$

where $\bar{A}($.$) denotes a second degree polynomial, and where \varepsilon_{i, 95}^{r}$ is an error term motivated by the presence of measurement error. It is distributed with density $f^{R}() . R a_{i}$, is the time invariant degree of risk aversion, upon which, schooling decisions depend. The background risk variables include the variance of GDP at the province level and a measure of subjective risk exposure, which was described earlier.

The wealth equation is given by

$$
\begin{aligned}
\text { Wealth }_{i, 95} & =\gamma_{X} \cdot X_{i}+\gamma_{S} \cdot S_{i}+Z_{i, 95} \gamma_{Z}+\gamma_{R} \cdot R a_{i}+\varepsilon_{i, 95}^{w} \\
& =W_{i} \gamma_{W}+\varepsilon_{i, 95}^{w}
\end{aligned}
$$

where $\varepsilon_{i, 95}^{w}$ is distributed with density $f^{W}()$. The vector of parameter, $\gamma_{X}$, measures the effect of parents' background variables on risk aversion while the parameter $\gamma_{S}$ allows us to detect if (or to what extent) wealth (and indirectly risk aversion) is explained by education. The vector $Z_{i, 95}$ contains a set of variables measured in 1995, and which may explain the transitory part of risk aversion. These variables include the capital gain on house property, the indicators dummies of the age of the father of the head of household, an indicator of house ownership as a result of gift or bequest, the sum of settlements received related to life, health, theft and casualty insurance and the contributions (in money or gifts) received from friends or family. These variables are indicated in Table 1 as capital_house, six dummies coh_f, housegift, insurance and friendsmoney.

To close the model, we approximate both $f^{r}($.$) and f^{w}()$ with a mixture of 5 unrestricted normal densities;

$$
f^{s}(.)=\sum_{m=1}^{M=5} P_{m}^{s} \cdot \phi\left(. ; \mu_{m}^{s}, \sigma_{m}^{s}\right) \text { for } s=W, R
$$

where $\phi\left(. ; \mu_{m}^{s}, \sigma_{m}^{s}\right)$ denotes the normal density with mean $\mu_{m}^{s}$ and standard deviation $\sigma_{m}^{s}$. 


\section{$5.3 \quad$ Heterogeneity}

Because we have a relatively complicated non-linear factor structure, and we have only a limited number of measurements on risk aversion, the distribution of the time invariant portion of risk aversion is difficult to identify. To perform estimation, we partition the domain of the permanent risk aversion factor into 6 points;

$$
\left\{R a_{1}=-0.02, R a_{2}=0.05, R a_{3}=0.12, R a_{4}=0.14, R a_{5}=0.17, R a_{6}=0.20\right\}
$$

These points are chosen to cover the same region as the Arrow-Pratt measure obtained in 1995. These support points, along with their respective type probabilities, define the degree of heterogeneity in risk aversion. ${ }^{17}$ Alongside, and in order to obtain full flexibility, we allow each risk aversion type to be endowed with a type specific set of grade hazard rate intercepts, $\alpha_{g i}$. Altogether, a type $k$ is defined as the subset of the population endowed with $\left\{\alpha_{1 k}, \alpha_{2_{k}}, \alpha_{3 k}, \alpha_{4 k}, R a_{k}\right\}$.

\subsection{Further Parameterization}

In order to estimate the model with normal mixtures and unobserved heterogeneity, the following parametrizations have been adopted.

Basically, we formulate the grade transition model as a mixture of normals with unit variance. To obtain identification, we impose the standard labeling condition (the components are ordered in ascending order in terms of their means: $\mu_{1}^{g}<\mu_{2}^{g} \ldots<\mu_{5}^{g}$ ), and for one component (the 3rd one), we set the mean $\left(\mu_{3}^{g}\right)$ to 0 . We do this because $X_{i}$ contains an intercept term (the individual specific heterogeneity term).

Finally, we proceed similarly for the wealth and the risk aversion equations. However, for both cases, we also estimate the variance (the $\sigma_{m}^{r}$ and $\left.\sigma_{m}^{w}\right)$ for each mixture component.

\section{Type probabilities:}

$$
p_{k},=\frac{\exp \left(p_{0 k}\right)}{\sum_{j=1}^{6} \exp \left(p_{0 j}\right)} \text { for } k=1,2, . .6 \text { and } p_{06}=0
$$

\section{Grade transitions (normal mixtures):}

\footnotetext{
${ }^{17}$ An alternative would be to define the residual of the risk aversion equation as individual specific risk aversion heterogeneity. However, this would only be valid in absence of measurement error.
} 


$$
\begin{gathered}
P_{m}^{g}=\frac{\exp \left(p_{m}^{g *}\right)}{\sum_{j=1}^{5} \exp \left(p_{j}^{g *}\right)} \text { for } m=1,2, . .5 \text { and } p_{5}^{g *}=0 \\
\mu_{1}^{g}=-\exp \left(\mu_{1}^{g *}\right)-\exp \left(\mu_{2}^{g *}\right), \\
\mu_{2}^{g}=-\exp \left(\mu_{2}^{g *}\right), \\
\mu_{3}^{g}=0 \\
\mu_{4}^{g}=\exp \left(\mu_{4}^{g *}\right), \\
\mu_{5}^{g}=\exp \left(\mu_{4}^{g *}\right)+\exp \left(\mu_{5}^{g *}\right) \\
\sigma_{m}^{g}=1 \text { for } m=1,2,3,4,5
\end{gathered}
$$

\section{Relative Risk aversion (normal mixtures):}

$$
\begin{gathered}
P_{m}^{r}=\frac{\exp \left(p_{m}^{r *}\right)}{\sum_{j=1}^{5} \exp \left(p_{j}^{r *}\right)} \text { for } m=1,2, . .5 \text { and } p_{5}^{r *}=0 \\
\mu_{1}^{r}=-\exp \left(\mu_{1}^{r *}\right)-\exp \left(\mu_{2}^{r *}\right), \\
\mu_{2}^{r}=-\exp \left(\mu_{1}^{r *}\right), \\
\mu_{3}^{r}=0 \\
\mu_{4}^{r}=\exp \left(\mu_{4}^{r *}\right), \\
\mu_{5}^{r}=\exp \left(\mu_{4}^{r *}\right)+\exp \left(\mu_{5}^{r *}\right) \\
\sigma_{m}^{r}=\exp \left(\sigma_{m}^{r *}\right) \text { for } m=1,2, . .5
\end{gathered}
$$

Wealth equation (normal mixtures):

$$
\begin{gathered}
P_{m}^{w}=\frac{\exp \left(p_{m}^{w *}\right)}{\sum_{j=1}^{5} \exp \left(p_{j}^{w *}\right)} \text { for } m=1,2, . .5 \text { and } p_{5}^{w *}=0 \\
\mu_{1}^{w}=-\exp \left(\mu_{1}^{w *}\right)-\exp \left(\mu_{2}^{w *}\right), \\
\mu_{2}^{w}=-\exp \left(\mu_{2}^{w *}\right), \\
\mu_{3}^{w}=0 \\
\mu_{4}^{w}=\exp \left(\mu_{4}^{w *}\right), \\
\mu_{5}^{w}=\exp \left(\mu_{4}^{w *}\right)+\exp \left(\mu_{5}^{w *}\right) \\
\sigma_{m}^{w}=\exp \left(\sigma_{m}^{w *}\right) \text { for } m=1,2, . .5
\end{gathered}
$$

\subsection{Estimation}

We estimate the model by maximum (mixed) likelihood techniques. The contribution to the likelihood for an individual $i$, who has completed level $g$, who is endowed with a wealth level $W$ ealt $h_{i, 95}$ and who reports a degree of absolute risk aversion $A_{i, 95}($.$) , is denoted L_{i}$, and is equal to

$$
\begin{gathered}
L_{i}=\sum_{k=1}^{K} p_{k} \cdot\left[\Pi_{s=1}^{g-1}\left(1-H_{s, i}\left(X_{i} \mid \text { type }_{k}\right)\right)^{s} \cdot H_{g, i}\left(X_{i}, \mid \text { type }_{k}\right)\right. \\
\cdot f^{R}\left(A_{i, 95}-\left(\bar{A}_{i, 95} \mid \text { type }_{k}\right)\right) \cdot \\
\left.f^{W}\left(\text { Wealth }_{i, 95}^{n i}-\left(W_{i} \gamma_{W} \mid \text { type }_{k}\right)\right)\right]
\end{gathered}
$$


where both $f^{R}($.$) and f^{W}($.$) are given by (8). The likelihood function is$ maximized using a Fortran based IMSL routine.

\section{An Overview of the Model Specifications}

In order to illustrate the potential endogeneity of risk aversion, we first estimate a model of grade transition in which the degree of absolute risk aversion (as measured in 1995) is taken as exogenous. This specification (referred to as Model 1) ignores the potential endogeneity of wealth, as well as measurement error. As a second step, we estimate the most general model specification in which risk aversion depends on wealth endowments and background risk variables (variance of GDP and the subjective risk measure) and in which wealth depends on long run factors such as education, relative risk aversion (the permanent portion) as well as transitory factors. This specification is referred to as Model 2. In both Model 1 and Model 2, we allow risk aversion to enter the last two stages of the decision making (transition to senior high school (given junior high school) and the transition to higher education (given completion of senior high school)). Finally, in Model 3, we re-evaluate the effect of risk aversion on the decision to enter higher education under the hypothesis that it is only relevant for the transition to higher education. We do this because decisions to go to senior high school are made at young age, and may therefore be influenced mostly by parents' background.

Because the model is highly non-linear and contains a large number of parameters (more than 200), it is more appealing to focus the discussion on the illustration of the marginal effects on the grade transition probabilities. ${ }^{18}$ For this reason, the entire set of parameters is found in appendix.

\section{$7 \quad$ Empirical Results}

As there exists a large literature which documents the determinant of schooling attainments, we focus our discussion on the effect of relative risk aversion on grade transitions (principally from senior high school to higher education but also from junior to senior high school.

\footnotetext{
${ }^{18}$ The degree of flexibility reached by using mixture of normals when modeling grade transition, wealth, and relative risk aversion is the main reason for the proliferation of parameters.
} 


\subsection{What is the effect of risk aversion on grade tran- sitions?}

Given the form of the hazard specification, it is important to note that the sign of the parameter estimates indicates the direction of the effect of a variable on the exit rate out of school. So, for instance, a positive (negative) estimate for the effect of risk aversion will typically imply that individuals who are more risk averse tend to have a higher (lower) drop out rate. For a particular grade level already completed, a positive effect of risk aversion therefore indicates that individuals regard entering the next grade level as risky, while a negative estimate would be consistent with the reverse argument (the insurance hypothesis).

In order to illustrate the results, we first computed the average hazard rates at three different levels of the individual specific (persistent) absolute risk aversion parameter; a low value corresponding to risk loving ( $R a=$ $-0.02)$, the population average and a high degree of risk aversion ( $R a=$ 0.20). These values span virtually the entire spectrum of the Arrow-Pratt measure computed in 1995. For the sake of comparison, and in order to provide a benchmark, we compare the effect of risk aversion to the effect of having been raised by parents who have both reached senior high school or higher education.

The drop-out rates are in Table 3, while the associated marginal effects (with standard errors) are found in Table 4. Without loss of generality, we calculate these hazard rates for type 1 individuals and for the modal occupation and region. We do this so that we can more easily compare risk aversion with parents' education (a key determinant of schooling attainments).

When endogeneity in risk aversion is ignored (Model 1), the marginal effect of risk aversion on the exit rate is positive for the transition to senior high school transition and negative for the transition to higher education. However, either the small difference between hazard rates calculated at $R a=$ -0.02 and at $R a=0.20$ (which are equal to 0.40 and 0.42 respectively) or the implied marginal effect found in table 4 (0.0050), indicate a very small effect for risk aversion. While the sign is reversed for the higher education transition, the marginal effect is even smaller (-0.0015). For the moment, we do not pay more attention to this sign reversal.

As argued earlier, the model that assumes exogenous risk aversion is questionable for 2 main reasons. First, risk aversion (as measured by 1995) is likely to be affected by current wealth which may have been affected by 
both long run factors (such as schooling) and transitory factors. Secondly, risk aversion is likely to be measured with error. Model 2 and Model 3 take these two issues into account.

There are two striking results. First, allowing for endogeneity causes a sign reversal in the effect of risk aversion on drop out rates. Given senior high school completion, we find that more risk averse individuals are more likely to drop after senior high school and disregard the higher education option. This is true in both Model 2 and Model 3 and it is consistent with the standard view that individuals regard higher education as risky. However, under the assumption that the degree of risk aversion is an input to the decision to continue to senior high school (Model 2), young individuals who are more risk averse are less likely to drop after junior high school.

The second striking result is the much higher marginal effects associated to risk aversion in both Model 1 and Model 2. Let's first focus on Model 2. At the junior high school-senior high school transition, the average drop out rate of those who are risk lover is equal to 0.41 while it is 0.28 for those who have strong risk aversion (Table 3 ). At the higher education transition, the equivalent numbers range from 0.44 to 0.53 . The relevant marginal effects $(-0.0323)$ and 0.0350 , found in Table 4, are indeed much higher in absolute term than in Model 1.

As the literature focuses on college (higher education) decisions, and as our estimates indicate that the effect of risk aversion depends on which grade level transition is considered, it is particularly important to investigate the robustness of the results for the higher education choice. In order to do this, we estimate a model (Model 3) where risk aversion affects only the decision to go to college. The results found in the 3rd column of both Table 3 and Table 4 still indicate that more risk averse individuals tend to drop after senior high school and opt out of higher education. The difference between the drop out of risk lovers (0.45) and risk averse individuals (0.49) has dropped slightly but it remains comparable to the effect of parents' education (which ranges from 0.44 to 0.47 ). To summarize, the results still point out to higher education as a risky investment.

\subsection{Is Risk Aversion Important?}

The effect of parental education is the natural benchmark marginal effect to use for comparison. The effect of parents' education is computed in Tables 3,4 and 5 as the difference in the drop out rate between individuals raised in 
families where both parents have reached senior high school degree or higher and individuals who belong to families where neither parent holds a senior high school degree. As documented in Tables 3 and 4, having both parents educated has an important effect on the drop out probability. More precisely, until one has reached senior high school, parents' education appear to be the dominant factor. However, our results indicate that the decision to attend higher education is dominated by attitudes toward risk.

In order to get a clearer picture, we decomposed the individual differences in drop out rates into two separate components; risk aversion and parents education. These estimates, found in Table 5, indicate that differences in risk aversion can account to up to $56 \%$ (in Model 2) and $46 \%$ (in Model 3) of the total variation in drop out rates before higher education. Risk aversion accounts only for $12 \%$ of the variation in drop out rates before senior high school enrollment.

Our findings are also robust to the inclusion of other instruments such as liquidity constraints indicators, and other variables such as state transfers, which are used in Guiso and Paiella (2001). ${ }^{19}$ To summarize, risk aversion is a key determinant of the decisions to enter higher education. In terms of importance, risk aversion is comparable to parents' educational background.

\subsection{The Distribution of Risk Aversion and Measure- ment Error}

In order to estimate the model, we must also estimate the distribution of the time invariant part of the risk aversion measure. This allows to separate the degree of absolute risk aversion measured in 1995 risk into 3 different components, one component that depends on wealth and background risk, another component representing the time invariant portion of risk aversion, and a residual term capturing measurement error. It is therefore interesting to compare its distribution to the actual Arrow-Pratt measure inferred in 1995 and evaluate the importance of measurement error.

In both Model 2 and Model 3, we find a measure of absolute risk aversion approximately equal to 0.10 (Table 6). This is lower than the actual measure inferred in 1995, which is equal to 0.15. As is evident from Table 7, measurement error is found to be most important. We find that the variance of the error term is 4 to 5 times as large as the variance of the regression.

\footnotetext{
${ }^{19}$ To reduce the burden of table presentation, we do not report them.
} 
Obviously, this high degree of measurement error explains the very weak correlation between risk aversion measures and grade completion reported in the empirical literature. Indeed, as reported in Belzil and Leonardi (2006), there is a very weak correlation between grade attainment and the betting price.

\subsection{The Effect of Wealth and Background Risk on Rel- ative Risk Aversion}

Because the link between risk aversion and its determinants is a complicated non-linear function, a look at the parameter estimates are not sufficient to evaluate the impact of all regressors. These effects will depend on the levels of the variables themselves and the interactions (Table 7). An informal way to proceed is to regress actual risk aversion on its determinants. Consistent with what is reported in Guiso and Paiella (2001), we find that risk aversion decreases with wealth and increases with both measures of background risk (the subjective income risk and the variance of the province GDP).

Subjective income risk is a measure of background risk and a higher background risk should be positively correlated with risk aversion. However the attitude towards risk presumably affects the choice of one's occupation, and more risk-averse individuals choose safer occupations. This tends to produce a negative correlation between earnings risk and risk aversion, counteracting the background-risk effect. Finally, the degree of risk aversion is increasing in the variance of per capita GDP in the province of residence. This is presumably a lower bound of the true effect of background risk because if risk-averse individuals tend to move from high-variance to low-variance provinces this would tend to generate a negative correlation between risk aversion and background risk.

\subsection{The Effect of Time Invariant Risk Aversion and Schooling on Wealth?}

The estimates of Table 8 indicate that wealth is positively associated with the individual level of education, as documented by the four dummy variables associated to different grade levels (higher education is the reference variable). Not surprisingly, it is also positively correlated with parents' education. Wealth is positively and significantly associated with all four variables 
which we use as exogenous instruments: the dummy for a house received as gift or bequest, the amount of money received as payment from insurance or from friends and relatives outside the household and the capital gain on the property house. Wealth is also positively related to the age of the head's father which we use as a proxy of the amount of inherited wealth. Finally, our model allows us to measure the effect of the individual specific (time invariant) degree of risk aversion on wealth. As more risk averse individuals may sometimes save more, but also invest in less risky assets, the sign of risk aversion on wealth is ambiguous. Our estimates indicate that risk aversion and wealth are negatively correlated. ${ }^{20}$

\section{Economic Interpretation and Concluding Re- marks}

In conclusion, we find that risk aversion is a key determinant of the decision to attend higher education and, to a certain extent, senior high school enrollment. More precisely, given senior high school completion, the decision to continue to higher education is negatively correlated with risk aversion. This result is robust to the allowance for potential effect of risk aversion at lower grade transitions. More importantly, it is consistent with standard theoretical arguments. ${ }^{21}$ It is also interesting to note that, conditional on senior high school completion, individual differences in risk aversion are as important as parents' educational background (the factor most often cited as the principal determinant of schooling attainments).

We also find that, conditional on junior high school completion, the decision to go to senior high school is increasing with risk aversion. Unlike for higher education, this result is harder to interpret, because senior high school incorporates a variety of academic as well as non academic streams (see Section 3). One possible interpretation is that individuals who obtain senior high school feel that this is a grade level sufficient to give them access to jobs that reduce their exposure to labor market risk. If reaching higher education does not reduce further risk exposure (from the demand side perspective), but entails specific supply side risks that are irrelevant at lower grade levels

\footnotetext{
${ }^{20}$ Interestingly, Guiso and Paiella (2001) also show that the negative relationship is robust to the introduction of the measures of background risk such as the variance of GDP at the provincial level and subjective (perceived) income uncertainty.

${ }^{21}$ See Lehvari and Weiss (1974).
} 
(for instance, when entering senior high school), then the decision to go to higher education would be negatively affected by risk aversion.

Finally, our results also point out to the impossibility of treating risk aversion (when measured after schooling decisions were made) as exogenous. Precisely, both wealth and measurement error are found to be important determinants of the post-schooling degree of absolute risk aversion.

Obviously, the econometric model is based on an argumentation that omits heterogeneity in subjective marginal risk evaluation. In a world where agents differ not only with respect to risk aversion, but also with respect to subjective probability distributions (some regard higher education as risky, others regard it as an insurance), the effect of risk aversion would be more difficult to evaluate. As a consequence, future research targeted at disentangling differences in risk aversion from differences in subjective risk evaluations appears an interesting avenue for future research. 


\section{References}

[1] Belzil, Christian (2007) "The Return to Schooling in Structural Dynamic Models: A Survey" forthcoming in The European Economic Review.

[2] Belzil, Christian and Hansen, Jörgen (2004) "Risk Aversion, Education and Earnings Dispersion" Research in Labor Economics, volume 23.

[3] Belzil, Christian and Marco Leonardi (2006) "Can Risk Aversion Explain Schooling Attainments", IZA Working paper 2123, forthcoming in Labour Economics

[4] Belzil, C. and Jörgen Hansen (2002) "Unobserved Ability and the Return to Schooling" Econometrica, 70(5), 2075-2091.

[5] Cameron, S. and James Heckman (1998) "Life Cycle Schooling and Dynamic Selection Bias: Models and Evidence for Five Cohorts of American Males" Journal of Political Economy, 106 (2), 262-333.

[6] Cameron, S. and James Heckman (2001) "The Dynamics of Educational Attainment of Black, Hispanic and White Males" Journal of Political Economy, 109(5), 455-499.

[7] Card, David and Thomas Lemieux (2000) "Dropout and Enrollments in the Post-War Period: What Went Wrong in the 1970's?" NBER Working Paper 7658.

[8] Chen, Stacey (2007) "Estimating the Variance of Wages in the Presence of Selection and Unobservable Heterogeneity" forthcoming in Review of Economics and Statistics.

[9] Chiswick, B.R. and Jacob Mincer (1972) "Time-series changes in Personal income inequality in the United states from 1939, with Projection 1985" Journal of Political Economy, 80(3), S34-S66.

[10] Cunha, F., J. Heckman and Salvador Navarro (2005) "Separating Uncertainty from Heterogeneity in Life Cycle Earnings" NBER Working Paper 11024.

[11] Eckstein, Zvi and Kenneth Wolpin (1999) "Why Youths Drop Out of High School: the Impact of Preferences, Opportunities and Abilities" Econometrica, 67(6), 1295-1339. 
[12] Geweke, J. and Michael Keane (1995) "Bayesian Inference for Dynamic Discrete Choice Models without the Need for Dynamic Programming" Working Paper, Federal reserve Bank of Minneapolis.

[13] Gollier, Christian (2001), The Economics of Risk and Time, The MIT Press.

[14] Guiso, L. and Monica Paiella (2001) "Risk Aversion, Wealth and Background Risk" CEPR Discussion Paper 2728.

[15] Guiso, L. and Monica Paiella (2005) "The Role of Risk Aversion in Predicting Individual Behaviour" Banca d'Italia Temi di Discussione 546.

[16] Guiso, L., T. Jappelli and L. Pistaferri (2002) "An Empirical Analysis of Earnings and Employment Risk" Journal of Business and Economic Statistics, 20, 1-13.

[17] Heckman, J., Lochner, L. and Petra Todd (2005) "Earnings Functions, Rates of Return, and Treatment Effects: The Mincer Equation and Beyond" NBER Working Paper 11544.

[18] Heckman, J. and Salvador Navarro (2005) "Dynamic Discrete Choices and Dynamic Treatment Effects" forthcoming in Journal of Econometrics.

[19] ISTAT (2003) "Lo Stato dell'Universita"' Istituto Nazionale di Statistica, Roma.

[20] Hartog, J., van Ophem, H. and Simona Bajdechi (2004) "How Risky is investment in Human Capital" Working Paper, Tinbergen Institute.

[21] Lehvari, D. and Yoram Weiss (1974) "The Effect of Risk on the Investment in Human Capital" American Economic Review, 64(6), 950-963.

[22] Lemieux, Thomas (2006) "Increasing Residual Wage Inequality: Composition Effects, Noisy Data, or Rising Demand for Skill?" American Economic Review, 3, 461-498.

[23] Mincer, Jakob (1974), Schooling, Experience and Earnings, New-York, Columbia University Press. 
[24] Olson, L., White, H. and H.M. Sheffrin (1979) "Optimal Investment in schooling when Incomes are Risky" Journal of Political Economy, 87(3), 522-539.

[25] Palacios-Huerta, Ignacio (2003) "An Empirical analysis of the Properties of Human Capital Returns" American Economic Review, 93 (3), 948964.

[26] Shaw Katryn (1996) "An Empirical Analysis of Risk Aversion and Income Growth," Journal of Labor Economics, 14, 626-653. 
Table 1: Descriptive statistics

\begin{tabular}{lrrrrr}
\hline \hline & & & & & \\
& obs & mean & std dev & min & max \\
risk aversion & 940 & 0.149 & 0.056 & -0.04 & 0.19998 \\
college_more & 940 & 0.141 & 0.349 & 0 & 1 \\
upper_highschool & 940 & 0.383 & 0.486 & 0 & 1 \\
lower_highschool & 940 & 0.321 & 0.467 & 0 & 1 \\
elementary & 940 & 0.143 & 0.350 & 0 & 1 \\
no_qualification & 940 & 0.012 & 0.108 & 0 & 1 \\
edu_father & 940 & 0.105 & 0.307 & 0 & 1 \\
edu_mother & 940 & 0.071 & 0.257 & 0 & 1 \\
north & 940 & 0.387 & 0.487 & 0 & 1 \\
south & 940 & 0.455 & 0.498 & 0 & 1 \\
female & 940 & 0.128 & 0.334 & 0 & 1 \\
bluecollar_f & 940 & 0.464 & 0.499 & 0 & 1 \\
selfempl_f & 940 & 0.304 & 0.460 & 0 & 1 \\
unempl_f & 940 & 0.007 & 0.086 & 0 & 1 \\
bluecollar_m & 940 & 0.123 & 0.329 & 0 & 1 \\
selfempl_m & 940 & 0.123 & 0.329 & 0 & 1 \\
unempl_m & 940 & 0.695 & 0.461 & 0 & 1 \\
age & 940 & 41.897 & 8.912 & 20 & 68 \\
coh_f_before1910 & 940 & 0.152 & 0.359 & 0 & 1 \\
coh_f_1910-19 & 940 & 0.231 & 0.422 & 0 & 1 \\
coh_f_1920-29 & 940 & 0.327 & 0.469 & 0 & 1 \\
coh_f_1930-39 & 940 & 0.183 & 0.387 & 0 & 1 \\
coh_f_1940-49 & 940 & 0.031 & 0.173 & 0 & 1 \\
coh_f_1950+ & 940 & 0.002 & 0.046 & 0 & 1 \\
wealth & 940 & 284535.900 & 381216.700 & -136000 & 4654000 \\
housegift & 940 & 0.398 & 0.999 & 0 & 11 \\
insurance & 940 & 399.979 & 3682.284 & 0 & 100000 \\
friendsmoney & 940 & 545.771 & 5756.831 & 0 & 135000 \\
capital_house & 940 & 121257.300 & 118442.600 & -394436 & 1070542 \\
subj_risk & 940 & 0.186 & 0.330 & 0 & 2.966 \\
var_gdp & 940 & 2.015 & 5.256 & 0.0005 & 22.262 \\
& & & & & \\
\hline
\end{tabular}


Table 2: The Individual Specific Arrow Pratt Measure of Risk Aversion

\begin{tabular}{ccc}
\hline \hline Deciles $A(w)$ & $\begin{array}{c}\text { Estimation } \\
\text { Sample }\end{array}$ & $\begin{array}{c}\text { Original } \\
\text { Sample }\end{array}$ \\
1 & -0.035 & -0.030 \\
2 & 0.028 & 0.017 \\
3 & 0.080 & 0.080 \\
4 & 0.115 & 0.115 \\
5 & 0.178 & 0.178 \\
6 & 0.189 & 0.193 \\
7 & 0.197 & 0.198 \\
8 & 0.199 & 0.199 \\
9 & 0.199 & 0.199 \\
& & \\
N obs. & 940 & 3,483 \\
\hline
\end{tabular}


Table 3: Average grade termination rates by degree of risk aversion and parents educations

\begin{tabular}{lccc}
\hline \hline & & & \\
Model & Model 1 & Model 2 & Model 3 \\
Risk aversion & exogenous & endogenous & endogenous
\end{tabular}

\section{Transition to elementary school}

Risk aversion

Parents' educ

$\begin{array}{llll}\text { high } & 0.0000 & 0.0000 & 0.0000 \\ \text { low } & 0.0002 & 0.0002 & 0.0020\end{array}$

Elementary to junior high school

Risk aversion

$\begin{array}{lllll}\text { Parents' educ } & \text { high } & 0.0000 & 0.0001 & 0.0000 \\ & \text { low } & 0.0453 & 0.0453 & 0.0456\end{array}$

Junior high school to senior high school

$\begin{array}{lllll}\text { Risk aversion } & R a_{i}^{*}=-0.02 & 0.4028 & 0.4114 & - \\ & R a_{i}^{*}=R a_{i}^{*} & 0.4182 & 0.3531 & - \\ & R a_{i}^{*}=0.20 & 0.4220 & 0.2783 & - \\ \text { Parents' educ } & \text { high } & 0.0128 & 0.0023 & 0.0064 \\ & \text { low } & 0.3524 & 0.2148 & 0.3292\end{array}$

Senior high school to college

$\begin{array}{lllll}\text { Risk aversion } & R a_{i}^{*}=-0.02 & 0.4634 & 0.4452 & 0.4506 \\ & R a_{i}^{*}=R a_{i}^{*} & 0.4578 & 0.4807 & 0.4795 \\ & R a_{i}^{*}=0.20 & 0.4559 & 0.5324 & 0.4870 \\ \text { Parents' educ } & \text { high } & 0.3524 & 0.4435 & 0.4355 \\ & \text { low } & 0.4519 & 0.4706 & 0.4663\end{array}$

30

Note: The intermediate value for risk aversion (average) are equal to 0.1485 (exogenous) and 0.1059 (endogenous) 0.0952 
Table 4: Grade termination function: Marginal effects

\begin{tabular}{|c|c|c|c|c|}
\hline \multirow[t]{2}{*}{$\begin{array}{l}\text { Model } \\
\text { Risk Aversion }\end{array}$} & $\begin{array}{c}\text { Model } 1 \\
\text { exogenous }\end{array}$ & $\begin{array}{c}\text { Model } 2 \\
\text { endogenous }\end{array}$ & \multicolumn{2}{|c|}{$\begin{array}{c}\text { Model } 3 \\
\text { endogenous }\end{array}$} \\
\hline & coeff $\quad$ std err & std err & coeff & std err \\
\hline \multicolumn{5}{|c|}{ Transition to elementary school } \\
\hline Risk aversion & - & - & - & \\
\hline Parents' educ & $-0.0002 \quad(0.003)$ & $-0.0002 \quad(0.003)$ & -0.0002 & $(0.002)$ \\
\hline \multicolumn{5}{|c|}{ Elementary to junior high school } \\
\hline Risk aversion & - & - & - & \\
\hline Parents' educ & $-0.0453 \quad(0.005)$ & $-0.0452 \quad(0.005)$ & -0.0456 & $(0.010)$ \\
\hline \multicolumn{5}{|c|}{ Junior high school to senior high school } \\
\hline Risk aversion & $(0.003)$ & $-0.0323 \quad(0.009)$ & - & \\
\hline Parents' educ & $-0.3544 \quad(0.087)$ & $-0.2125 \quad(0.096)$ & -0.3229 & $(0.055)$ \\
\hline \multicolumn{5}{|c|}{ Senior high school to college } \\
\hline Risk aversion & $-0.0015 \quad(0.007)$ & $(0.087)$ & 0.0141 & $(0.003)$ \\
\hline Parents' educ & $-0.0896 \quad(0.023)$ & $-0.0271 \quad(0.022)$ & -0.0308 & $(0.006)$ \\
\hline
\end{tabular}


Table 5: The relative explanatory power of risk aversion and parents' education

Model $\quad$ Model $1 \quad$ Model $2 \quad$ Model 3

Risk Aversion exogenous endogenous endogenous

Junior high school to senior high school

Risk aversion $\quad 2 \% \quad 12 \%$

Parent's educ $\quad 98 \% \quad 88 \% \quad 100 \%$

Senior high school to college

Risk aversion $\quad 1 \% \quad 56 \% \quad 43 \%$

Parent's educ $\quad 99 \% \quad 44 \% \quad 57 \%$ 
Table 6: The distribution of time invariant risk aversion

\begin{tabular}{lcc}
\hline \hline & $\begin{array}{c}\text { Model } 2 \\
\text { type probability }\end{array}$ & $\begin{array}{c}\text { Model } 3 \\
\text { type probability }\end{array}$ \\
$R a_{i}^{*}=-0.02$ & 0.19 & 0.24 \\
$R a_{i}^{*}=0.05$ & 0.17 & 0.20 \\
$R a_{i}^{*}=0.12$ & 0.16 & 0.14 \\
$R a_{i}^{*}=0.14$ & 0.16 & 0.13 \\
$R a_{i}^{*}=0.17$ & 0.15 & 0.13 \\
$R a_{i}^{*}=0.20$ & 0.17 & 0.17 \\
& & \\
average & & \\
st. dev & 0.1059 & 0.0952 \\
& 0.07 & \\
\hline
\end{tabular}


Table 7: Absolute Risk Aversion equations

\begin{tabular}{|c|c|c|c|c|}
\hline & \multicolumn{2}{|c|}{$\begin{array}{c}\text { Model } 2 \\
\text { endogenous }\end{array}$} & \multicolumn{2}{|c|}{$\begin{array}{c}\text { Model } 3 \\
\text { endogenous }\end{array}$} \\
\hline & coeff & std err & coeff & std err \\
\hline Wealth & -0.0044 & 0.0083 & 0.0206 & 0.0118 \\
\hline Wealth square & 0.0051 & 0.0007 & 0.0107 & 0.0007 \\
\hline var gdp & -0.0432 & 0.0039 & 0.0046 & 0.0049 \\
\hline var gdp square & -0.0864 & 0.0038 & -0.0009 & 0.0008 \\
\hline subj risk & -0.2064 & 0.0027 & -0.1587 & 0.0012 \\
\hline subj risk square & 0.2178 & 0.0040 & 0.2874 & 0.0018 \\
\hline Wealth*var gdp & -0.0002 & 0.0024 & -0.0077 & 0.0021 \\
\hline Wealth*subj risk & -0.0864 & 0.0097 & -0.0468 & 0.0048 \\
\hline subj risk*var gdp & -0.0311 & 0.0159 & -0.0240 & 0.0129 \\
\hline$R a_{i}^{*}$ & 0.0021 & 0.0027 & -0.1250 & 0.0028 \\
\hline$R a_{i}^{*}$ square & 0.0396 & 0.0058 & 0.0804 & 0.0066 \\
\hline$R a_{i}^{*}{ }^{*}$ wealth & -0.0494 & 0.0056 & -0.0697 & 0.0072 \\
\hline$R a_{i}^{*} *^{*}$ subj risk & 0.0851 & 0.0049 & 0.1145 & 0.0032 \\
\hline$R a_{i}^{*} *_{\operatorname{var}} \operatorname{gdp}$ & -0.0071 & 0.0071 & 0.0124 & 0.0061 \\
\hline Variance Regression & 0.2476 & & 0.2480 & \\
\hline Variance Error term & 0.8956 & & 1.1261 & \\
\hline
\end{tabular}


Table 8: Wealth equation

\begin{tabular}{|c|c|c|c|c|}
\hline \multirow[t]{2}{*}{$\begin{array}{l}\text { Model } \\
\text { Risk aversion }\end{array}$} & \multicolumn{2}{|c|}{$\begin{array}{c}\text { Model } 2 \\
\text { endogenous }\end{array}$} & \multicolumn{2}{|c|}{$\begin{array}{c}\text { Model } 3 \\
\text { endogenous }\end{array}$} \\
\hline & coeff & std err & coeff & std err \\
\hline upper_highschool & -0.6822 & 0.0021 & -0.6499 & 0.0017 \\
\hline lower_highschool & -1.4022 & 0.0015 & -1.4001 & 0.0017 \\
\hline elementary & -1.507 & 0.0011 & -1.5061 & 0.0011 \\
\hline no_qualification & -1.4994 & 0.0009 & -1.4996 & 0.0009 \\
\hline edüfather & 0.177 & 0.0011 & 0.1857 & 0.001 \\
\hline edu_mother & 1.2917 & 0.001 & 1.2944 & 0.0009 \\
\hline bluecollar_f & -0.2383 & 0.0017 & -0.2281 & 0.002 \\
\hline bluecollar_m & 1.0987 & 0.001 & 1.0981 & 0.001 \\
\hline selfempl_f & 0.4507 & 0.0015 & 0.4682 & 0.0014 \\
\hline selfempl_m & 1.4043 & 0.0011 & 1.4009 & 0.0011 \\
\hline unempl_f & -0.5994 & 0.0009 & -0.5998 & 0.0009 \\
\hline unempl_m & 1.1207 & 0.0031 & 1.1669 & 0.0027 \\
\hline north & 0.6634 & 0.0015 & 0.6751 & 0.0017 \\
\hline south & -0.0903 & 0.0022 & -0.0581 & 0.0019 \\
\hline female & -0.9217 & 0.0012 & -0.9097 & 0.001 \\
\hline age45more & -0.2716 & 0.0137 & -0.1997 & 0.017 \\
\hline coh_f_1910-19 & -0.5095 & 0.0013 & -0.5101 & 0.0013 \\
\hline coh_f_-1920-29 & -0.8213 & 0.0014 & -0.8165 & 0.0015 \\
\hline coh_f_1930-39 & -0.7459 & 0.0014 & -0.7272 & 0.0011 \\
\hline coh_f_-1940-49 & -0.911 & 0.001 & -0.9063 & 0.0009 \\
\hline coh_f_- $1950+$ & -1.301 & 0.0009 & -1.3005 & 0.0009 \\
\hline house_gift & 0.769 & 0.0027 & 0.8078 & 0.0018 \\
\hline insurance & 0.1972 & 0.0009 & 0.1983 & 0.0009 \\
\hline friends_money & 0.7966 & 0.0009 & 0.7979 & 0.0009 \\
\hline capital_gain & 0.7923 & 0.0042 & 0.8165 & 0.0051 \\
\hline risk_aversion & -0.1546 & 0.0071 & -0.2258 & 0.0078 \\
\hline
\end{tabular}


Table 1: Appendix. Type probabilities and Normal Mixtures

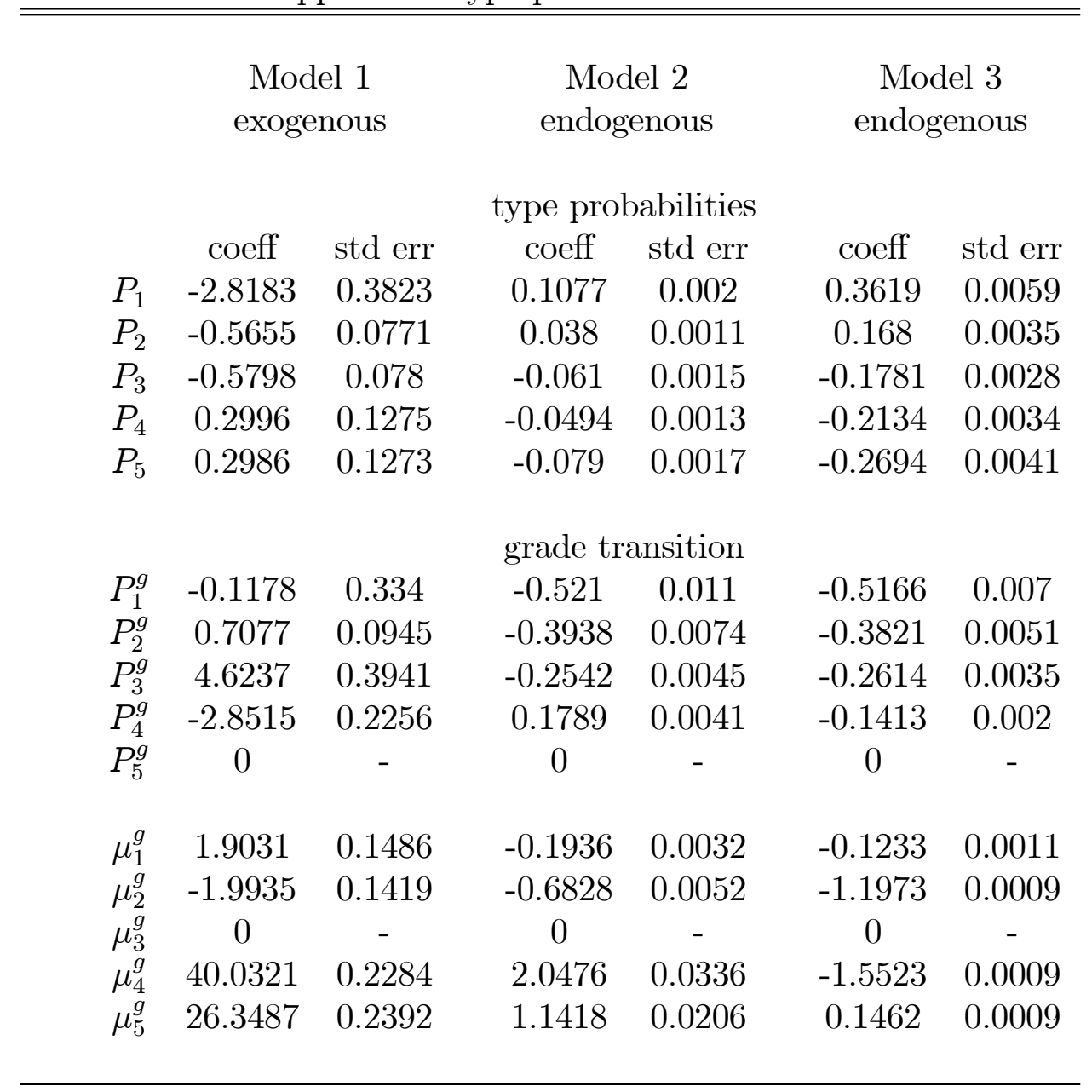


Table 2: Appendix. Normal Mixtures: risk aversion equation

\begin{tabular}{|c|c|c|c|c|}
\hline & \multicolumn{2}{|c|}{$\begin{array}{c}\text { Model } 2 \\
\text { endogenous }\end{array}$} & \multicolumn{2}{|c|}{$\begin{array}{c}\text { Model } 3 \\
\text { endogenous }\end{array}$} \\
\hline & coeff & std err & coeff & std err \\
\hline$P_{1}^{r}$ & -0.6342 & 0.0166 & -0.3689 & 0.0062 \\
\hline$P_{2}^{r}$ & 0.1402 & 0.0037 & 0.0836 & 0.0016 \\
\hline$P_{3}^{r}$ & 0.1552 & 0.0042 & 0.0902 & 0.0017 \\
\hline$P_{4}^{r}$ & 0.1701 & 0.0046 & 0.0973 & 0.0019 \\
\hline$P_{5}^{r}$ & 0 & 0.0009 & 0 & 0.0009 \\
\hline$\mu_{1}^{r}$ & -1.9926 & 0.0009 & -1.9903 & 0.0009 \\
\hline$\mu_{2}^{r}$ & -2.004 & 0.001 & -1.9951 & 0.0009 \\
\hline$\mu_{3}^{r}$ & -1 & 0.0009 & -1 & 0.0009 \\
\hline$\mu_{4}^{r}$ & -1.9942 & 0.0009 & -1.9956 & 0.0009 \\
\hline$\mu_{5}^{r}$ & -1.0114 & 0.001 & -1.0016 & 0.0009 \\
\hline$\sigma_{1}^{r}$ & 0.2172 & 0.0065 & 0.3246 & 0.0071 \\
\hline$\sigma_{2}^{r}$ & -0.0316 & 0.0023 & 0.0178 & 0.0013 \\
\hline$\sigma_{3}^{r}$ & -0.119 & 0.0044 & -0.033 & 0.0017 \\
\hline$\sigma_{4}^{r}$ & -0.2017 & 0.0066 & -0.0777 & 0.0023 \\
\hline$\sigma_{5}^{r}$ & -0.2623 & 0.0093 & -0.0773 & 0.0032 \\
\hline
\end{tabular}


Table 3: Appendix. Normal Mixtures: wealth equation

\begin{tabular}{|c|c|c|c|c|}
\hline & \multicolumn{2}{|c|}{$\begin{array}{c}\text { Model } 2 \\
\text { endogenous }\end{array}$} & \multicolumn{2}{|c|}{$\begin{array}{c}\text { Model } 3 \\
\text { endogenous }\end{array}$} \\
\hline & coeff & std err & coeff & std err \\
\hline$P_{1}^{w}$ & -0.8148 & 0.001 & -0.8184 & 0.0009 \\
\hline$P_{2}^{w}$ & -0.1258 & 0.003 & -0.1727 & 0.0014 \\
\hline$P_{3}^{w}$ & -0.4221 & 0.0011 & -0.4318 & 0.0009 \\
\hline$P_{4}^{w}$ & -0.5323 & 0.001 & -0.5258 & 0.0009 \\
\hline$P_{5}^{w}$ & 0 & 0.0009 & 0 & 0.0009 \\
\hline$\mu_{1}^{w}$ & -1.4988 & 0.0009 & -1.4989 & 0.0009 \\
\hline$\mu_{2}^{w}$ & -1.4928 & 0.001 & -1.4955 & 0.001 \\
\hline$\mu_{3}^{w}$ & 0 & 0.0009 & 0 & 0.0009 \\
\hline$\mu_{4}^{w}$ & -1.5122 & 0.001 & -1.5092 & 0.001 \\
\hline$\mu_{5}^{w}$ & -1.5048 & 0.001 & -1.5045 & 0.0009 \\
\hline$\sigma_{1}^{w}$ & 0.9648 & 0.0149 & 1.2227 & 0.0051 \\
\hline$\sigma_{2}^{w}$ & 0.4957 & 0.0286 & 0.9929 & 0.0097 \\
\hline$\sigma_{3}^{w}$ & 0.7937 & 0.0205 & 1.1485 & 0.007 \\
\hline$\sigma_{4}^{w}$ & 0.9523 & 0.0164 & 1.2398 & 0.0057 \\
\hline$\sigma_{5}^{w}$ & 1.6648 & 0.0053 & 1.6153 & 0.0032 \\
\hline
\end{tabular}


Table 4: Appendix. Parameter estimates: Model 1

\begin{tabular}{lcccc}
\hline \hline & $\begin{array}{c}\text { Transition to } \\
\text { elementary }\end{array}$ & $\begin{array}{c}\text { Elementary to } \\
\text { junior high }\end{array}$ & $\begin{array}{c}\text { Junior high to } \\
\text { senior high }\end{array}$ & $\begin{array}{c}\text { Senior high to } \\
\text { college }\end{array}$ \\
& & & & \\
$\alpha_{g 1}$ & -4.3925 & -3.8904 & -1.7909 & 1.5419 \\
$\alpha_{g 2}$ & -4.9126 & -4.3504 & -1.6655 & 2.0462 \\
$\alpha_{g 3}$ & -4.9111 & -4.3516 & -1.6613 & 2.0407 \\
$\alpha_{g 4}$ & -4.8795 & -4.4867 & -1.8957 & 2.3619 \\
$\alpha_{g 5}$ & -3.9706 & -4.4866 & -1.8957 & 2.3618 \\
$\alpha_{g 6}$ & -4.8794 & -5.9394 & -4.15 & 1.6852 \\
& & & & \\
edu_f & -2.4847 & -3.2026 & -0.7906 & $-0.0887^{*}$ \\
edu_m & -1.0169 & $-0.077^{*}$ & -0.3251 & -0.7607 \\
bluec_f & 1.0425 & 1.3045 & 1.128 & 0.5129 \\
bluec_m & -0.2322 & 0.9441 & 0.8857 & $0.3101^{*}$ \\
self_f & -1.8988 & 1.1488 & 0.9409 & 0.2765 \\
self_m & -2.8585 & 0.5979 & 0.9206 & $0.1454^{*}$ \\
unempl_f & $-0.1004^{*}$ & 1.1899 & 1.0258 & 3.2324 \\
unempl_m & -0.352 & 0.607 & 0.8484 & -0.1579 \\
north & -2.6503 & $-0.0525^{*}$ & -0.2389 & -0.1801 \\
south & 2.3323 & 0.1979 & $-0.0156^{*}$ & -0.2502 \\
female & -2.1524 & $-0.0312^{*}$ & $0.0766^{*}$ & -0.2312 \\
risk_av & & & 0.1075 & -0.0566 \\
& & & & \\
\hline Note: Allmodels & & & & \\
\hline
\end{tabular}

Note: All models include a set of nine 5-years age dummies. All coefficients are significant at the $1 \%$ level except those with *. 
Table 5: Appendix. Parameter estimates: Model 2

\begin{tabular}{|c|c|c|c|c|}
\hline & $\begin{array}{l}\text { Transition to } \\
\text { elementary }\end{array}$ & $\begin{array}{l}\text { Elementary to } \\
\text { junior high }\end{array}$ & $\begin{array}{l}\text { Junior high to } \\
\text { senior high }\end{array}$ & $\begin{array}{l}\text { Senior high to } \\
\text { college }\end{array}$ \\
\hline$\alpha_{g 1}$ & -3.8266 & -1.765 & -0.2272 & 0.6548 \\
\hline$\alpha_{g 2}$ & -3.817 & -1.6692 & -0.2249 & 0.6057 \\
\hline$\alpha_{g 3}$ & -3.8028 & -1.611 & -0.2114 & 0.5602 \\
\hline$\alpha_{g 4}$ & -4.0597 & -1.6197 & -0.21 & 0.56 \\
\hline$\alpha_{g 5}$ & -3.9706 & -1.6112 & -0.2083 & 0.5557 \\
\hline$\alpha_{g 6}$ & -4.0564 & -1.7025 & -0.2265 & 0.5726 \\
\hline edu_f & -1.6834 & -2.0917 & -1.8599 & -0.5224 \\
\hline edu_m & -0.4712 & -2.5042 & -1.4438 & -0.386 \\
\hline bluec_f & 2.5779 & 0.5697 & 1.4876 & 0.9129 \\
\hline bluec_m & 0.1269 & 0.7332 & 0.7537 & 0.8483 \\
\hline self_f & 1.566 & 0.524 & 1.2237 & 0.5723 \\
\hline self_m & -0.7616 & 0.6104 & 0.4573 & 0.4472 \\
\hline unempl_f & -0.0225 & 0.6835 & 1.6748 & 3.2276 \\
\hline unempl_m & -0.9491 & -1.0875 & 0.4225 & 0.7258 \\
\hline north & -0.359 & -1.0324 & -0.4563 & 0.119 \\
\hline south & 1.7296 & -0.6568 & -0.0644 & 0.0521 \\
\hline female & 0.3283 & 0.2476 & 0.1203 & 0.0858 \\
\hline risk_av & & & -0.3707 & 1.2131 \\
\hline
\end{tabular}

Note: All models include a set of nine 5-years age dummies. All coefficients are significant at the $1 \%$ level except those with *. 
Table 6: Appendix. Parameter estimates: Model 3

\begin{tabular}{lcccc}
\hline \hline & $\begin{array}{c}\text { Transition to } \\
\text { elementary }\end{array}$ & $\begin{array}{c}\text { Elementary to } \\
\text { junior high }\end{array}$ & $\begin{array}{c}\text { Junior high to } \\
\text { senior high }\end{array}$ & $\begin{array}{c}\text { Senior high to } \\
\text { college }\end{array}$ \\
$\alpha_{g 1}$ & -2.9744 & -1.8698 & -0.4086 & 0.6141 \\
$\alpha_{g 2}$ & -2.3444 & -1.6524 & -0.3358 & 0.5622 \\
$\alpha_{g 3}$ & -2.2199 & -1.5477 & -0.2857 & 0.5314 \\
$\alpha_{g 4}$ & -2.2273 & -1.5426 & -0.2816 & 0.5311 \\
$\alpha_{g 5}$ & -2.0871 & -1.4956 & -0.2452 & -0.2974 \\
$\alpha_{g 6}$ & -2.2061 & -1.9941 & -0.4321 & 0.5793 \\
& & & & \\
edu_f & -1.6913 & -2.0804 & -1.8771 & -0.5579 \\
edu_m & -0.4773 & -2.4979 & -1.4572 & -0.4089 \\
bluec_f & 2.3385 & 0.5197 & 1.119 & 0.8386 \\
bluec_m & 0.0499 & 0.641 & 0.632 & 0.8275 \\
self_f & 1.4484 & 0.4202 & 0.9792 & 0.5326 \\
self_m & -0.803 & 0.5115 & 0.3445 & 0.4377 \\
unempl_f & -0.0233 & 0.6839 & 1.6665 & 3.2248 \\
unempl_m & -1.2105 & -1.0205 & -0.0052 & 0.5889 \\
north & -0.4494 & -1.0296 & -0.7037 & 0.034 \\
south & 1.4743 & -0.7093 & -0.3652 & -0.0251 \\
female & 0.2883 & 0.2392 & 0.0252 & 0.056 \\
risk_av & & & & 0.9088 \\
& & & & \\
\hline Note: All mode & & & & \\
\hline
\end{tabular}

Note: All models include a set of nine 5-years age dummies. All coefficients are significant at the $1 \%$ level except those with * 